by computed tomography in our patient. Although the lesion was discernible in retrospect, it was not possible to make a confident diagnosis from the images obtained at the time. Finally, these tumours in patients with acquired cystic disease of the kidney have a metastatic potential of $5 \%$, but the current consensus is that lesions under $3 \mathrm{~cm}$ diameter should be treated conservatively. ${ }^{3.5} \mathrm{Al}$ though there was no evidence of metastatic spread in our patient, the tumour had invaded deeply into the renal cortex, and we would therefore suggest that this policy is kept under critical review.

N J VINER

A G MACIVER

J C MACKENZIE

Departments of Nephrology

and Pathology,

Southmead Hospital,

Bristol BS10 5NB

1 Bommer J, Waldherr R, Van Kaick C, Strauss L, Ritz E. Acquired renal cysts in uraemic patients-in vivo demonstration by computed tomography. Clin Nephrol 1980;14:299-303. 2 Chung-Park M, Ricanati E, Lankerani M, Kedia K. Acquired renal cysts and multiple renal cell and urothelial tumours. $A m \mathcal{F}$ Clin Pathol 1983;79:238-42.

3 Ishikawa I. Uraemic acquired cystic disease of the kidney Urology 1985;26:101-8.

4 Grantham JL, Levine E. Acquired cystic disease: replacing one kidney disease with another kidney. Kidney Int 1985;28: 99-105.

5 Bretan PN, Busch MP, Hricak H, Williams RD. Chronic renal failure: a significant risk factor in the development of acquired failure: a significant risk factor in the development of acquired
renal cysts and renal cell carcinoma. Cancer 1986;57:1871-9.

\section{Raised concentrations of plasma atrial natriuretic peptides in cardiac transplant recipients}

SIR,-We read with interest the report by $\mathrm{Dr}$ Donald R J Singer and others (29 November, p 1391). We have measured plasma immunoreactive atrial natriuretic peptide (ANP) concentrations in five cardiac transplant recipients after one hour at rest (sitting) and during a period of lower body positive pressure. The latter is a complex stimulus but we have shown that it results in an increase in right and left atrial dimension, systemic blood pressure, and plasma immunoreactive ANP concentrations in healthy volunteers. ${ }^{1}$

The five cardiac transplant recipients were all men, aged 28 to 53 years (mean 38 years), who had had their transplants 15 to 80 months (mean 38.6 (SD 11) months) earlier. All were well and showed no signs of rejection or cardiac failure. Mean (SEM) blood pressure was $123 / 78(4 \cdot 8 / 3 \cdot 9) \mathrm{mm} \mathrm{Hg}$ and serum creatinine $149.5(16.4) \mu \mathrm{mol} / 1$. They were taking the following medication: cyclosporin (4), azathioprine (3), prednisolone (3), nifedipine retard (2), diuretics (3), methyldopa (1), and hydralazine (1).

These patients followed the same protocol as our healthy volunteers.' They attended a hospital sideroom on two mornings. After one hour sitting at rest they wore a medical antishock trouser (MAST) suit for one hour. On one occasion for each volunteer this was inflated to $40 \mathrm{~mm} \mathrm{Hg}$ pressure. After 60 minutes the suit was removed and the patients remained sitting for a further hour. Blood was taken before inflating the suit (time 0 ) and at 5, 20, and 60 minutes of suit inflation and at 90 minutes - that is, 30 minutes after the suit had been removed. Plasma immunoreactive ANP concentration was measured by radioimmunoassay. ${ }^{2}$

The cardiac transplant recipients had a higher mean basal plasma immunoreactive ANP concentration than our healthy volunteers $(n=6$; aged 20 to 28 years) by a factor of 9 (table). This is greater than that reported by Dr Singer and colleagues, but our two study groups were not

Mean (SEM) basal plasma immunoreactive ANP concentration and response to lower body positive pressure in healthy volunteers $(n=6)$ and cardiac transplant recipients $(n=5)$

Plasma immunoreactive ANP $(\mathrm{pmol} / \mathrm{l})$

Time (mins) Healthy volunteers ${ }^{\star} \quad$ Transplant recipients

\begin{tabular}{lll}
\hline 0 & $5 \cdot 7(1 \cdot 1)$ & $58 \cdot 7(12 \cdot 6)$ \\
$\begin{array}{l}\text { Inflation } \\
5\end{array}$ & $5 \cdot 3(0 \cdot 7)$ & \\
20 & $8 \cdot 9(1 \cdot 8) \dagger$ & $58 \cdot 2(10 \cdot 5)$ \\
60 & $9 \cdot 8(1 \cdot 3) \dagger$ & $69 \cdot 2(11 \cdot 3)$ \\
90 & $5 \cdot 7(0.8)$ & $94.0(15 \cdot 1) \dagger$ \\
\end{tabular}

*Values for healthy volunteers reproduced by kind permission of the editor, Fournal of Hypertension.

tp $<0.05$ compared with time 0 .

matched. Our healthy volunteers were younger, had lower blood pressures, and had normal renal function, all of which may have enhanced but would not have accounted for the difference in ANP values between the two groups. Plasma immunoreactive AN: concentration was raised in our one patient (aged 30 years) with normal blood pressure and renal function $\mathbf{8 0}$ months after transplantation. There was a tendency within the group for ANP values to fall with time since transplantation.

Plasma immunoreactive ANP values increased in all five patients during lower body positive pressure. The response seemed to be more delayed in the transplant recipients than in the healthy volunteers. The percentage rise at 20 minutes (mean (SEM) 128.8 (15.1)\%) was less than that for our healthy volunteers $(157 \cdot 8(9 \cdot 7) \%)$ but at 60 minutes the difference was less pronounced $(171 \cdot 2$ $(13.4) v 189(28.6) \%)$

There was no significant change in mean plasma immunoreactive ANP concentration in either group on the non-inflation day. The blunted rise in ANP concentrations in response to lower body positive pressure compared with that in healthy controls is in keeping with the observations of Tomlanovitch et al, who (using urinary cyclic guanosine monophosphate as a measure of ANP activity) found an attenuated response to water immersion in a group of cardiac transplant recipients. ${ }^{3}$ The explanation for this blunting effect in these patients is unclear but may in part be due to increased atrial size, which might dilute the expected increase in atrial dimension after lower body positive pressure.

M R WILKINS M D GAMMAGE HELEN M LEWIS L B TAN

Departments of Pharmacology and Cardiology, University of Birmingham,

Birmingham B15 2TJ

1 Wilkins MR, Gammage MD, Tan LB, et al. Effect of lower-body positive-pressure on atrial dimension and plasma atrial natriuretic peptide concentration. $f$ Hypertension (in press)

2 Wilkins MR, Wood JA, Adu D, et al. Change in plasma immunoreactive atrial natriuretic peptide concentration during sequential ultrafiltration and haemodialysis. Clin $\mathrm{Sci}$ 1986;71:157-60.

3 Tomlanovitch S, Peterson C, Molina C, et al. Role of atrial natriuretic hormone (ANH) and cardiac nerves in renal response to hypervolaemia in man. Clinical Research 1986;34: $702 \mathrm{~A}$.

\section{Heat inactivation of specimens_-AIDS}

SIR,-Our attention has been drawn to some apparent misunderstanding of the wording of paragraph 61 of the revised guidelines on AIDS issued by the Advisory Committee on Dangerous Pathogens in July of this year (LAVIHTLV IIIThe Causative Agent of AIDS and Related Conditions. $\mathrm{HN}(86) 20)$.
The impression in some quarters is that this paragraph implies that the AIDS virus is not 3 susceptible to heat treatment. This is not the message which it was intended to convey. Spire etc $a l$ reported on the successful inactivation of viral enzyme by what might be regarded as the standard heat treatment regimen-namely, $56^{\circ} \mathrm{C}$ for $30^{\circ}$ minutes. ${ }^{1}$ But a later paper by Resnick et al cast some doubt on the efficacy of inactivation of the virus over this period. ${ }^{2}$

Although Resnick et al showed that the high:titred virus they used was inactivated by tenfold in 20 minutes, there is to our knowledge no reliable estimate of the range of infectious virus titres or the rate of inactivation of virus in the serum of $\overline{\bar{N}}$ naturally infected subjects. Little could therefore be said about what combination of time and temperature would give a reasonable margin of safety. Also, there appears to be little or no information on the effects of longer heating times. on serum analytes. Most published work refers $\overrightarrow{-}$ only to periods of 30 to 60 minutes.

The committee was therefore unable, without further supporting evidence, to recommend any particular heat treatment regimen. Thus in para-ĩ graph 61 of the revised guidelines the use of the phrase "practical heat treatment procedure" was intended to convey both uncertainty about the duration of heating required to achieve inactiva- + tion of the virus and the lack of information on the $\vec{N}$ reliability of results obtained from subsequent $\mathrm{N}$ tests.

\section{Michael Chapman -} Peter Lister

Joint Secretariat of the Advisory Committee on Dangerous Pathogens,

DHSS,

London SE1 6TE

1 Spire B, Dormont B, Barré-Sinoussi F, Montagnier L, Chermann JC. Inactivation of lymphadenopathy-associated virus by heat, " gamma rays, and ultraviolet light. Lancet 1985; i: 188-9.

2 Resnick L, Veren K, Salahuddin SZ, Tondreau S, Markham PD. 은 Stability and inactivation of HTLV-HI/LAV under clinical and laboratory environments. JAMA 1986;255:1887-91.

\section{Primary pulmonary hypertension}

SIR, - We would like to clarify one or two matters which seem to have been obscured in Dr Timo Higenbottam's leading article (6 December, $\mathrm{p}$ 1456).

It is fundamental to understand that gas transfer for carbon monoxide is always low in primary pulmonary hypertension because of a greatly reduced pulmonary capillary volume secondary toํ constriction or obliteration of pulmonary arterioles. Primary pulmonary hypertension due to this cause 0 has to be distinguished from pulmonary venoocclusive disease and also from thromboembolic $\sigma$ pulmonary hypertension, in neither of which is $D$ there benefit from vasodilator drugs. The clinical and radiological signs, incidentally, are of the $N$ pulmonary hypertension and not of the raised pulmonary vascular resistance which causes this $\omega$ hypertension.

Treatment is aimed both towards raising the lowe cardiac output and to reducing the pulmonary $\bar{D}$ artery pressure in the hope of retarding progression of hypertensive damage to the lung bed. ${ }^{2} 2$

A good response to a vasodilator is most likely in ${ }^{-}$ patients who are discovered at an earlier stage of $\mathbb{D}$

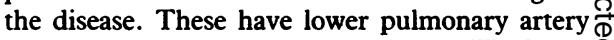
pressures and higher cardiac outputs. We found $\varrho$ that the acute response to prostacyclin was no better at predicting the degree of reversible vasoconstriction than the response to nifedipine buto had the virtue of being immediately reversible in the event of an unfavourable response with a fall in $\frac{0}{\partial}$ systemic blood pressure. Since oral nifedipine was : 